\title{
Systematic Review of the Economic Burden of Overt Hepatic Encephalopathy and Pharmacoeconomic Impact of Rifaximin
}

\author{
Guy Neff ${ }^{1} \cdot$ Woodie Zachry III ${ }^{2}$
}

Published online: 12 April 2018

(C) The Author(s) 2018, corrected publication [May 2018]

\begin{abstract}
Background Hepatic encephalopathy (HE), a common neurologic complication in cirrhosis, is associated with substantial disease and economic burden. Rifaximin is a non-systemic antibiotic that reduces the risk of overt HE recurrence and overt HE-related hospitalizations.

Objective Our objective was to provide an overview of the direct HE-related costs and cost benefits of rifaximin, lactulose, and rifaximin plus lactulose.

Methods A systematic review of PubMed and relevant meeting abstracts was conducted to identify publications since 1 January 2007 reporting economic data related to $\mathrm{HE}$ and rifaximin and/or lactulose. Further, a public database and published literature were used to estimate current costs of hospitalization for overt $\mathrm{HE}$, and potential cost savings of HE-related hospitalizations with rifaximin. The methodological quality of included studies was evaluated using the Drummond checklist.

Results A total of 16 reports were identified for inclusion in the systematic review. Globally, HE-related direct costs ranged from $\$$ US5370 to $\$$ US50,120 annually per patient. Rifaximin was associated with shorter hospital stays and reduced healthcare costs. Rifaximin also has the potential to reduce overt HE-related hospitalization risk by $50 \%$ compared with lactulose. Rifaximin was shown to have a
\end{abstract}

The original version of this article was revised due to a retrospective Open Access Order.

Guy Neff

guy.neff@fdhs.com

1 Florida Research Institute, Florida Digestive Health Specialists, Lakewood Ranch, FL, USA

2 Quantym Therapeutic Data, Sarasota, FL, USA favourable pharmacoeconomic profile compared with lactulose (based on the incremental cost-effectiveness ratio). Conclusions In addition to its clinical benefits (e.g. reduction in the risk of recurrence of overt HE, overt HErelated hospitalizations, favourable adverse event profile), economic data are favourable for the use of rifaximin in patients with a history of overt HE.

\section{Key Points for Decision Makers}

Hepatic encephalopathy (HE) is associated with substantial healthcare utilization (e.g. hospitalizations), which rifaximin has been shown to reduce (e.g. reduction in risk of overt HE recurrence, reduction in overt HE-related hospitalizations).

The economic burden of HE on healthcare systems, including annual hospitalizations for patients with overt HE, may be mitigated by rifaximin.

The cost savings and clinical benefits of rifaximin in patients with cirrhosis have the potential to benefit healthcare decision making regarding management of HE.

\section{Introduction}

Hepatic encephalopathy (HE) is a common neurologic complication of cirrhosis [1] and is estimated to affect between 30 and $70 \%$ of patients with cirrhosis [2, 3]. Cognitive impairment experienced by patients with $\mathrm{HE}$ ranges 
from minimal (covert) HE, which is detected using specialized testing, to overt HE, which is characterized by clinically identifiable symptoms (e.g. confusion, personality and behavioural changes, lethargy) [1,4]. HE negatively impacts multiple aspects of the lives of patients (e.g. cognition, employment, finances) $[5,6]$ and their caregivers (e.g. personal health, finances, daily life) [6]. HE adversely affects sleep quality and sleep efficiency (i.e. time spent sleeping while in bed) [7] and is associated with learning impairment, which may persist even when overt HE symptoms clinically resolve $[8,9]$. Both general (e.g. physical functioning, social functioning) and disease-specific (e.g. disease effects, memory) health-related quality-of-life (HRQOL) indicators are aberrantly affected in patients with HE compared with patients without the condition $[10,11]$. In one study, $100 \%$ of patients with overt HE reported depressive symptoms in the previous 2 weeks, a finding that had a significant negative association with all domains of the general and diseasespecific HRQOL instruments used to assess patient functioning $(p=0.03$ to $p<0.001)$ [10].

Patients with a history of $\mathrm{HE}$ are at increased risk for HE recurrence; one study estimated that risk of recurrence increased by $23 \%$ with every unit increase in the number of prior overt $\mathrm{HE}$ episodes (hazard ratio (HR) 1.23; $95 \%$ confidence interval (CI) 1.19-1.29) [12]. It is not uncommon for patients with overt HE to require hospitalization to manage the condition [13-15]; indeed, in a prospective study of patients with cirrhosis, overt HE was the most common cause of patients' initial liver diseaserelated hospitalizations [15]. Further, HE was predictive of cirrhosis-related rehospitalization (odds ratio (OR) 5.5; 95\% CI 2.0-15.3; $p=0.001$ ) [16]. A study of patients with cirrhosis in a US hospital system reported that overt HE was the most common cause for rehospitalization in community hospitals compared with tertiary-care hospitals (29.5 vs. 8.6\%, respectively) [17]. Furthermore, post-index mean annual hospital costs (2010-2013) for patients with an index hospitalization for complications of cirrhosis, such as HE, were greater for patients rehospitalized $\leq 30$ or $>30$ days than for patients who were not readmitted and had outpatient costs only (\$US73,252 and 62,053 vs. 5719 , respectively) [17]. Based on findings of two independent studies conducted in the USA and Canada, an estimated $18.1 \%$ of patients with cirrhosis who had been hospitalized previously had an HE-related rehospitalization within 30 days, and an estimated $23.7-28.8 \%$ of patients reported an HE-related readmission within 3 months $[18,19]$. A study of patients with HE-related hospitalizations observed that $38.4 \%$ were readmitted within 30 days, and an additional $13.6 \%$ reentered the hospital within 31-90 days of their last stay [20]. An Italian study estimated that $42.5 \%$ of patients with a previous overt HE-related hospitalization experienced another such rehospitalization within 1 year [21]. Another Italian study of patients previously hospitalized for liver disease estimated that this population experienced a mean of 1.5 HE-related readmissions annually during the 3-year period from 2006 through 2008 [13].

Given the substantial healthcare utilization associated with HE, the aim of this systematic review is to provide an overview of the global costs associated with HE and of management options that have the potential to decrease healthcare utilization in a manner that may be beneficial to patients and healthcare institutions.

\section{Methods}

\subsection{Reference Search}

A PubMed search of English language articles available from 1 January 2007 through 23 June 2017 was conducted using the following keywords to identify articles for inclusion in the review: hepatic encephalopathy, economic, health-related quality of life, cost, cost utility, cost effectiveness, rifaximin, lactulose, adherence, and patient-reported outcomes. Abstracts presented at annual meetings of the American Association for the Study of Liver Diseases (AASLD), the European Association for the Study of the Liver (EASL), and Digestive Disease Week, between 2014 and 2017 (if available), were reviewed for inclusion in the article. The International Society for Pharmacoeconomics and Outcomes Research abstract database [22] was also searched for inclusion of relevant studies published between 2014 and 2017. Data from the Agency for Healthcare Research and Quality's Healthcare Cost and Utilization Project [23] were used to determine annual hospitalizations for patients with HE, which were coded according to one of three International Classification of Diseases, Ninth Revision, Clinical Modification (ICD-9-CM) codes for HE: 291.2 (alcoholic dementia, not elsewhere classified), 348.30 (encephalopathy, not otherwise specified), and 572.2 (hepatic coma) [23].

\subsection{Inclusion}

Publications selected for inclusion during formal review were those that reported on economic evaluations of patients with $\mathrm{HE}$ and patients with $\mathrm{HE}$ receiving rifaximin, lactulose, or rifaximin plus lactulose. Further, studies examining quality of life (QOL) in patients with $\mathrm{HE}$ and $\mathrm{HE}$ as an outcome in patients with cirrhosis were considered for inclusion in this review. Studies were excluded if patients included were aged $<18$ years, did not receive rifaximin and/or lactulose, or had minimal (or covert) HE. Narrative reviews were also excluded. 


\subsection{Assessment of Methodological Quality of Economic Studies}

The 10-item Drummond checklist was used to evaluate the quality of methods reported for the economic studies identified for inclusion in this systematic review [24]. Criteria for exclusion of economic studies were a combined lack of economic importance of the research question, failure to identify competing alternatives, and outcomes not relevant to the current review. No studies identified for inclusion in this review were excluded based on this quality assessment.

\section{Results}

\subsection{Identification of Studies}

The search for economic studies related to HE that were published since 2007, as well as studies related to the use of lactulose and/or rifaximin for the management of HE, found 133 articles or abstracts, of which 16 were identified for inclusion in this systematic review because they contained cost data related to overt HE (Fig. 1). Specifically, nine articles (including two systematic reviews) were identified as being related to economic costs of overt HE, and seven articles or abstracts were considered related to costs associated with rifaximin and/or lactulose for patients with overt HE. Excluded from further review were review articles (excluding systematic reviews) and studies of paediatric patients or minimal or covert HE, as well as studies that included other HE treatments or did not include economic data.

\subsection{Economic Impact of Hepatic Encephalopathy}

Data from the US Nationwide Inpatient Service indicate that the number of HE-related hospitalizations increased annually between 2004 and 2014, excepting 2008 (from 95,232 in 2004 to 156,205 in 2014) [23]. Further, in 2014, for patients with a primary diagnosis of HE (ICD-9-CM diagnosis code $572.2 ; n=55,485$ ), unadjusted (for the medical consumer price index) total costs were estimated at approximately \$US620 million [23]. These data from the US Nationwide Inpatient Service [23], and data in published studies (Table 1) [21, 25-32], demonstrate the economic impact of HE-related hospitalizations.

A systematic review of 11 economic costs studies for countries with available data (excluding the USA) published between 1990 and 2011 estimated mean annual HErelated costs at $\$ \mathrm{US} 13,270$ per patient (range 5370-50,120); the methodologies for collecting cost data for each study included in the systematic review were highly variable [26]. A systematic review of US studies of patients with hepatitis C-related sequelae estimated that annual HE-related costs were \$US16,430 in the first year and \$US3810 annually in subsequent years, although these values are likely an underestimate of current costs, given that many studies included in the systematic review relied on a small single-centre study from 1997 [25]. The broad range of economic costs observed are consistent with the findings of this systematic review of seven independent studies examining economic costs associated with HE worldwide (Table 1) [21, 27-32]: we found a broad range of mean annual hospitalization costs (2012) for patients with HE, with between \$US25,634 and \$US58,625 reported for the USA [32].

\subsection{Management of Hepatic Encephalopathy and Clinical Impact}

Management of overt HE includes treating patients with acute HE episodes, preventing HE recurrence, and identifying and managing precipitating factors associated with development of HE [1]. First-line therapy for patients experiencing an acute episode of overt HE is the nonabsorbable disaccharide lactulose, which requires self-titration to two to three soft bowel movements per day [1]. Rifaximin is an oral non-systemic antibiotic approved in the USA for reduction of risk of overt HE recurrence in adults; the recommended dosing is $550 \mathrm{mg}$ twice daily. Guidelines from the AASLD and EASL recommend rifaximin as add-on therapy to lactulose to reduce the risk of overt HE recurrence [1].

\subsubsection{Lactulose for Hepatic Encephalopathy}

A meta-analysis of 22 randomized controlled studies demonstrated that nonabsorbable disaccharides (i.e. lactulose, lactitol) were significantly more effective than placebo or no intervention for the prevention and treatment of HE (relative risk (RR) 0.58 ; 95\% CI 0.48-0.69) [33]. A meta-analysis of 24 randomized controlled studies demonstrated that nonabsorbable disaccharides significantly reduced the risk of mortality compared with placebo or no intervention (RR 0.59; 95\% CI 0.40-0.87) [33]. For hospitalized patients with end-stage liver disease, lactulose use was associated with decreased risk of Clostridium difficile infection (OR $0.48 ; 95 \%$ CI $0.31-0.74 ; p<0.001$ ) [34], which is important given that $C$. difficile infection is associated with poor outcomes in hospitalized patients with cirrhosis (i.e. higher mortality rate, longer hospital stay, increased hospital costs) [35]. 


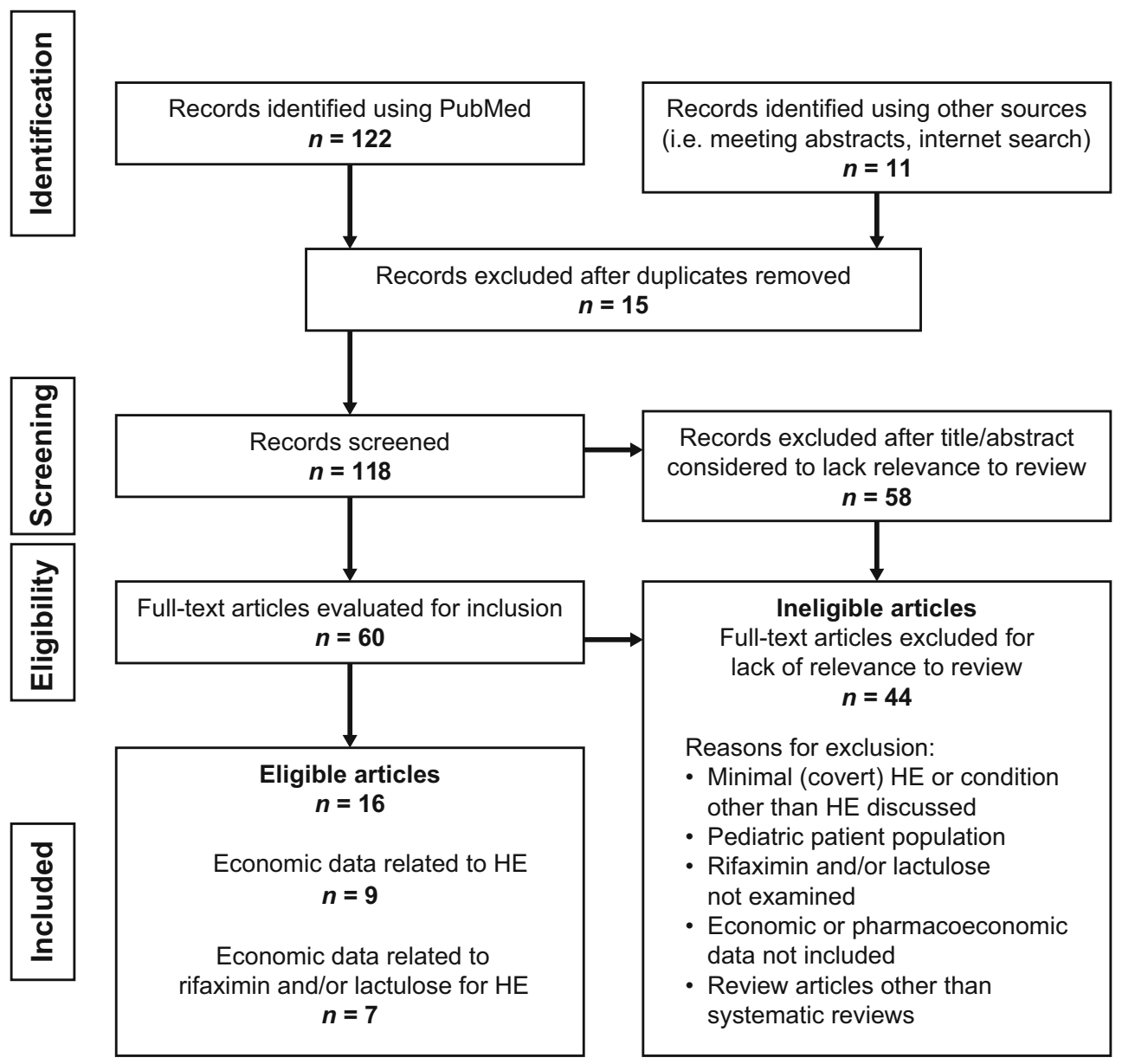

Fig. 1 Preferred Reporting Items for Systematic Reviews and MetaAnalyses (PRISMA) diagram detailing the search for records pertaining to economic data for hepatic encephalopathy, and administration of rifaximin and/or lactulose. Search terms included hepatic

\subsubsection{Rifaximin for the Management of Hepatic Encephalopathy}

Rifaximin is indicated in the USA for reducing the risk of overt HE recurrence in adults but not for management of an acute episode of overt HE. However, in one study, a significantly greater percentage of patients receiving rifaximin plus lactulose experienced complete reversal of an acute overt HE episode compared with those receiving lactulose alone after 10 days $(76.2$ vs. $43.9 \%$, respectively; $p=0.004)$ [36]. Rifaximin plus lactulose was associated with decreased mortality compared with lactulose alone (23.8 vs. $49.1 \% ; p<0.05)$ [36]. In addition, rifaximin has demonstrated efficacy for reducing the risk of overt HE recurrence. In a Greek study, rifaximin decreased the risk of overt HE recurrence $(p=0.03)$ and improved survival $(p=0.01)$ in patients with alcohol-related decompensated cirrhosis compared with patients not receiving rifaximin during a 5-year period [37]. In a US single-centre encephalopathy, economic, health-related quality of life, cost, cost utility, cost effectiveness, rifaximin, lactulose adherence, and patientreported outcomes. $H E$ hepatic encephalopathy

retrospective study, a significantly lower percentage of patients receiving rifaximin and lactulose combination therapy for acute HE were rehospitalized for HE-related reasons within 6 months compared with patients receiving lactulose alone (2.4 vs. $16.2 \%$, respectively; $p=0.03$ ) [38]. In a 6-month phase III randomized, double-blind, placebocontrolled study in patients with a history of overt HE $(n=299)$, rifaximin reduced the risk of breakthrough $\mathrm{HE}$ by $58 \%$ (HR $0.42 ; 95 \%$ CI $0.28-0.64 ; p<0.001$ ) compared with placebo; of note, $91 \%$ of patients in each group received concomitant lactulose [39]. Twice-daily rifaximin improved sleep quality after 28 days in patients with a history of HE [7]. Finally, a meta-analysis of 12 randomized controlled studies of patients with minimal or overt HE demonstrated that rifaximin significantly decreased the risk of mortality compared with lactulose/lactitol, other antibiotics, or placebo (RR 0.64; 95\% CI 0.43-0.94) [40].

A retrospective chart review of patients with overt HE demonstrated the durability of rifaximin for the 
Table 1 Economic costs associated with hepatic encephalopathy

\begin{tabular}{|c|c|c|c|}
\hline Study; country; perspective & Population & Outcome(s) & Cost(s) \\
\hline $\begin{array}{l}\text { Irish et al. [32]; USA; payer } \\
\text { perspective }\end{array}$ & $\begin{array}{l}\text { Pts with HE-related hospitalization } \\
\text { in 2012; Medicare claims database } \\
(n=1113)\end{array}$ & $\begin{array}{l}\text { Mean no. of hospitalizations: } \\
2.4 \\
\text { Mean duration of } \\
\text { hospitalization: } 5.9 \text { days } \\
\text { Mean no. of outpatient visits: } \\
11.0\end{array}$ & $\begin{array}{l}\text { Mean hospitalization costs: } \\
\text { \$US25,364-58,625 }\end{array}$ \\
\hline $\begin{array}{l}\text { Poovorawan et al. [27]; Thailand; } \\
\text { payer perspective }\end{array}$ & $\begin{array}{l}\text { Pts with cirrhosis (ICD-10 code } \\
\text { K74)-related hospitalization in } \\
2010(n=92,301 \text { admissions }) \\
\text { Pts with HE }(n=5292)\end{array}$ & $\begin{array}{l}\text { Mean } \pm \text { SD duration of HE- } \\
\text { related hospitalization: } \\
9.1 \pm 10.9 \text { days } \\
\text { Mortality during } \\
\text { hospitalization: } 32 \%\end{array}$ & $\begin{array}{l}\text { Mean } \pm \text { SD hospitalization costs: } \\
\text { THB44,606 } \pm 71,001 \\
\text { \$US1394 } \pm 2219 \\
\text { Total healthcare costs: } \\
\text { THB58,134 } \pm 79,763 \\
\text { \$US1817 } \pm 2493\end{array}$ \\
\hline $\begin{array}{l}\text { Roggeri et al. [21]; Italy; payer } \\
\text { perspective }\end{array}$ & $\begin{array}{l}\text { Pts with } \geq 1 \text { overt HE-related } \\
\text { hospitalization between } 1 \text { January } \\
2011 \text { and } 31 \text { December } 2011 \\
(n=381)\end{array}$ & $\begin{array}{l}\text { Mortality } \\
\text { During index hospitalization } \\
\quad(n=82 ; 21.5 \%) \\
\text { During hospitalization at } \\
1 \text {-year follow-up }(n=22 \text {; } \\
5.8 \%) \\
\text { Mean } \pm \text { SD duration of } \\
\text { overt HE recurrence- } \\
\text { related hospitalization: } \\
9 \pm 7 \text { days }\end{array}$ & $\begin{array}{l}\text { Mean } \pm \text { SD direct costs of single } \\
\text { overt HE recurrence-related } \\
\text { hospitalization }{ }^{\text {a }} € 3361 \pm 1286 \text {; } \\
\$ U S 3838 \pm 1469 \\
\text { Total annual costs for pts with } \\
(n=124) \text { and without }(n=172) \\
\text { overt HE recurrence: } € 21,272 \\
(\$ U S 24,293) \text { vs. } € 12,098 \\
(\$ U S 13,816) \text {, respectively } \\
(p<0.001) \\
\text { Mean } \pm \text { SD annual hospitalization } \\
\text { cost with recurrence vs. no } \\
\text { recurrence: } € 18,970 \pm 16,652 \\
\text { vs. } € 10,196 \pm 22,182 \\
\text { Mean } \pm \text { SD annual drug cost with } \\
\text { recurrence vs. no recurrence: } \\
€ 1633 \pm 1807 \text { vs. } \\
€ 1173 \pm 1657 \\
\text { Mean } \pm \text { SD annual diagnostic and } \\
\text { therapeutic procedure costs with } \\
\text { recurrence vs. no recurrence: } \\
€ 669 \pm 974 \text { vs. } € 729 \pm 1519\end{array}$ \\
\hline $\begin{array}{l}\text { Benković et al. [28]; Croatia; payer } \\
\text { perspective }\end{array}$ & $\begin{array}{l}\text { Pts with malnutrition and HE in } \\
2012(n=945)\end{array}$ & & $\begin{array}{l}\text { Total healthcare costs: } € 1,019,994 \\
\text { Mean healthcare costs/pt: } € 1344\end{array}$ \\
\hline $\begin{array}{l}\text { Lee et al. [29]; China; payer } \\
\text { perspective }\end{array}$ & $\begin{array}{l}\text { Pts with HE (ICD-9-CM diagnosis } \\
\text { code 572.2) associated with } \\
\text { benzodiazepine use enrolled in } \\
\text { previous (2005-2009) and current } \\
\text { (2009-2012) clinical studies at } \\
\text { single hospital }(n=322)\end{array}$ & & $\begin{array}{l}\text { Mean } \pm \text { SD HE-related healthcare } \\
\text { costs } \\
\text { Hospitalization: NTD6987 } \pm 419 \text {; } \\
\text { \$US231 } \pm 14 \\
\text { Outpatient visits: NTD812 } \pm 99 \\
\text { \$US27 } \pm 3 \\
\text { ER visits: NTD4170 } \pm 641 ; \\
\text { \$US138 } \pm 21 \\
\text { Overall medical costs: } \\
\text { NTD11,970 } \pm 210 ; \\
\text { \$US396 } \pm 7\end{array}$ \\
\hline
\end{tabular}


Table 1 continued

\begin{tabular}{|c|c|c|c|}
\hline Study; country; perspective & Population & Outcome(s) & $\operatorname{Cost}(\mathrm{s})$ \\
\hline $\begin{array}{l}\text { Andersen et al. [30]; Denmark; } \\
\text { provider perspective }\end{array}$ & $\begin{array}{l}\text { Pts with cirrhosis with previous HE- } \\
\text { related hospitalization receiving } \\
\text { outpatient rehabilitation (2009; } \\
n=19 \text { ) vs. pts not receiving } \\
\text { rehabilitation (i.e. control group; } \\
2008 ; n=14 \text { ) }\end{array}$ & $\begin{array}{l}\text { Survival ( } \leq 20 \text { months from } \\
\text { baseline; rehabilitation } \\
\text { group vs. control group): } \\
84 \text { vs. } 36 \%, \text { respectively; } \\
p=0.01\end{array}$ & $\begin{array}{l}\text { Median (range) costs } \\
\text { Rehospitalization at study } \\
\text { hospital } \\
\text { Rehabilitation group: DKK52,266 } \\
\quad(0-409,402) \text {; \$US } 9643 \\
\quad(0-75,535) \\
\text { Control group: DKK51,266 } \\
\text { (0-410,128); \$US9459 } \\
\text { (0-75,669) } \\
\text { Rehospitalization at any hospital } \\
\text { Rehabilitation group: DKK84,730 } \\
\text { (0-409,402); \$US15,633 } \\
\text { (0-75,535) } \\
\text { Control group: DKK84,395 } \\
\text { (0-471,562); \$US15,571 } \\
(0-87,004)\end{array}$ \\
\hline $\begin{array}{l}\text { El Khoury et al. [26]; Brazil, } \\
\text { Canada, Asia-pacific region, } \\
\text { Europe (systematic review); } \\
\text { payer }(n=3 \text { studies) and provider } \\
(n=7 \text { studies) perspective; } \\
\text { perspective unknown for } 1 \text { study }\end{array}$ & $\begin{array}{l}\text { Pts with HE related to HCV } \\
\text { infection } \\
\text { Studies published between January } \\
1990 \text { and January } 2011 \text { ( } n=11 \\
\text { studies) }\end{array}$ & & $\begin{array}{l}\text { Mean (range) global HE-related } \\
\text { costs }(2010 \text { values): } \$ \text { US13,270 } \\
(5370-50,120)\end{array}$ \\
\hline $\begin{array}{l}\text { El Khoury et al. [25]; USA } \\
\text { (systematic review); provider } \\
\text { perspective ( } n=5 \text { studies) }\end{array}$ & $\begin{array}{l}\text { Pts with HE associated with HCV } \\
\text { infection } \\
\text { Studies published between } 1997 \text { and } \\
2007(n=5)\end{array}$ & & $\begin{array}{l}\text { Mean HE-related costs }(2010 \\
\text { values) } \\
\text { Year 1: \$US16,430 } \\
\text { Year 2: \$US3810 }\end{array}$ \\
\hline $\begin{array}{l}\text { Stepanova et al. [31]; USA; payer } \\
\text { perspective }\end{array}$ & $\begin{array}{l}\text { Pts with HE-related hospitalizations } \\
\text { between } 2005 \text { and } 2009 \\
(n=111,090)\end{array}$ & $\begin{array}{l}\text { Mean } \pm \text { SD duration of HE- } \\
\text { related hospitalization } \\
\text { 2005: } 8 \pm 0.2 \text { days } \\
\text { 2009: } 8.5 \pm 0.2 \text { days } \\
\text { Mean no. procedures } \\
\text { 2005: } 1.9 \pm 0.1 \\
\text { 2009: } 2.2 \pm 0.1 \\
\text { In-hospital mortality } \\
\text { 2005: } 15.6 \% \\
\text { 2009: } 14.4 \%\end{array}$ & $\begin{array}{l}\text { Total HE-related hospitalization } \\
\text { charges } \\
\text { 2005: \$US4.677 billion } \\
\text { 2009: \$US7.254 billion } \\
\text { Mean HE-related hospitalization } \\
\text { charges } \\
\text { 2005: \$US } 46,663 \pm 2180 \\
\text { 2009: \$US63,107 } \pm 3244 \\
\text { Mean HE-related costs per pt } \\
\text { 2005: \$US16,512 } \pm 709 \\
\text { 2009: \$US17,812 } \pm 764\end{array}$ \\
\hline
\end{tabular}

$D K K$ Danish krone, $E R$ emergency room, $H C V$ hepatitis $\mathrm{C}$ virus, $H E$ hepatic encephalopathy, ICD-9-CM International Classification of Diseases, Ninth Revision, Clinical Modification, ICD-10 ICD, Tenth Revision, mo month, NTD New Taiwan dollars, $p t$ patient, $S D$ standard deviation, THB Thai baht

${ }^{\mathrm{a}}$ Exchange rate $€ 1.00=\$ \mathrm{US} 1.1420$

maintenance of $\mathrm{HE}$ remission, as $81.2 \%$ of 149 patients receiving monotherapy (mean duration 255 days) and $66.7 \%$ of 54 patients receiving rifaximin and lactulose combination therapy (mean duration 205 days) did not experience HE recurrence during 1 year of follow-up [41]. In that study, of the $28(18.8 \%)$ patients receiving rifaximin monotherapy and the $18(33.3 \%)$ receiving rifaximin with lactulose who experienced breakthrough $\mathrm{HE}, 42.9$ and $38.9 \%$ required hospitalization for overt $\mathrm{HE}$, respectively, and 14.3 and $27.8 \%$ required hospitalization for dehydration and overt HE, respectively [41]. In another US singlecentre study, rifaximin significantly reduced the odds of rehospitalization within 30 days in patients with overt $\mathrm{HE}$ (OR 0.39; 95\% CI 0.16-0.87; $p=0.02$ ) [42]. Rifaximin 
was associated with a decrease in hospitalizations [43]; in one study, 30-day and 6-month rehospitalization rates in patients with $\mathrm{HE}$ receiving rifaximin $550 \mathrm{mg}$ twice daily were 9.4 and $15.6 \%$, respectively [44]. Patients with HE who were crossed over from placebo to receive open-label rifaximin in a randomized controlled trial had a numeric decrease in HE-related hospitalizations within 6 months, although significance was not achieved (0.36 vs. 0.57 events/person-years of exposure; $p=0.4$ ) [43]. In a phase III randomized controlled trial of patients with a history of overt HE $(n=299)$, rifaximin $550 \mathrm{mg}$ twice daily reduced the risk of HE-related hospitalization by $50 \%$ compared with placebo during a 6-month period (HR 0.50; 95\% CI $0.29-0.87 ; p=0.01$ ); overall, 13.6 and $22.6 \%$ of patients, respectively, experienced HE-related hospitalizations [39]. In a long-term open-label study, rifaximin was associated with decreased rates of overt $\mathrm{HE}$ - and all-cause-related hospitalizations for $\geq 2$ years compared with patients receiving placebo for $\geq 6$ months (historical comparison group) [45]. A single-centre retrospective study reported that patients with more severe liver disease (i.e. Model for End-Stage Liver Disease (MELD) score $>20 ; n=43$ ) receiving rifaximin plus lactulose for $\geq 6$ months had a lower mean number of HE-related hospitalizations than did patients with a MELD score $<20(n=49 ; 1.6$ vs. 2.5 hospitalizations, respectively) [46]. However, retrospective analysis of a US pharmacy claims database (1 January 2006 through 30 June 2015) found no difference in overt HE-related hospitalizations between rifaximin plus lactulose vs. lactulose monotherapy (16.0 vs. $15.3 \%$, respectively; $p=0.8$ ) [47]. Furthermore, there was no significant reduction in the risk of an overt $\mathrm{HE}$ episode between the two groups (HR 1.04; 95\% CI 0.81-1.28) [47]. These findings are currently limited to presentation in abstract form, and it is unclear why these data differ from the positive data noted above. The abstract authors speculated that this difference may be related to unobserved confounding [47]. Overall, data support that rifaximin is effective for reducing all-cause- and HE-related hospitalizations in patients with a history of overt $\mathrm{HE}$.

\subsection{Impact of Therapy on Hepatic Encephalopathy Costs and Outcomes}

Rifaximin and lactulose combination therapy has been shown to significantly decrease the duration of hospital stays vs. lactulose alone $(5.8 \pm 3.4$ vs. $8.2 \pm 4.6$ days; $p=0.001$ ) [36], even given the higher monthly drug cost of rifaximin vs. lactulose [48, 49]. Congly and Leise [48] suggested a favourable economic impact of rifaximin on hospitalizations. Lactulose was associated with significantly worse adherence (i.e. taking $\geq 75 \%$ of doses as prescribed by patient self-report) compared with rifaximin in a single-centre retrospective study of patients with $\mathrm{HE}$ receiving lactulose twice daily for $\geq 6$ months, followed by rifaximin alone three times daily for $\geq 6$ months (31 vs. $92 \%$, respectively; $p<0.001$ ) [50]. In that study, during the $\geq 6$-month timeframe, lactulose was associated with a greater number of hospitalizations than was rifaximin alone (1.6 vs. 0.5 , respectively; $p<0.001)$ as well as longer duration of hospitalization ( 7.3 vs. 2.5 days; $p<0.001$ ) and higher hospitalization costs per patient (\$US56,635 vs. 14,222; year 2005 values; payer perspective) [50]. Data from a single-centre retrospective study of patients receiving lactulose monotherapy found that dehydration and failure to adhere to therapy were predictors of $\mathrm{HE}$ recurrence [51]. A US single-centre retrospective study of patients hospitalized for $\mathrm{HE}$ indicated that lactulose use after initial hospitalization was a significant factor associated with rehospitalization within 90 days (OR 8.6; $95 \% \mathrm{CI}$ 1.1-66.7; $p=0.03$ ); however, rifaximin use posthospitalization was not significantly associated with risk of rehospitalization within 90 days (OR 1.2; 95\% CI 0.7-2.2; $p=0.3$ ) [52].

The adverse effects associated with lactulose, including diarrhoea, abdominal pain, and bloating, were associated with nonadherence to lactulose and resulted in a failure to adequately titrate lactulose to the appropriate number of daily bowel movements [51]; in one study, failure to properly titrate lactulose was a common cause of preventable rehospitalization in patients with $\mathrm{HE}$ who were readmitted within 1 month of their last hospital stay [53]. A significantly greater percentage of patients experienced diarrhoea, flatulence, and abdominal pain with lactulose compared with rifaximin alone $(p<0.001$, for each comparison) [50]. Further, a meta-analysis of eight controlled clinical studies demonstrated that rifaximin had a more favourable safety profile than lactulose, as the risks of diarrhoea and abdominal pain were significantly less with rifaximin than with lactulose (diarrhoea RR 0.11 ; $95 \% \mathrm{CI}$ $0.04-0.31 ; p<0.0001$; abdominal pain RR 0.34; 95\% CI $0.14-0.83 ; p=0.02$; both adverse events together RR 0.19 ; 95\% CI $0.10-0.37 ; p<0.00001$ ) [54]. Nonadherence to lactulose, in part related to adverse events, appeared to play a role in HE recurrence and HE-related rehospitalization, both events that are associated with economic costs that may be avoidable in some patients.

In the UK, healthcare resource utilization was significantly decreased after initiation of rifaximin compared with before initiation of rifaximin (Table 2) [55, 56]. In one study, use of rifaximin (with $87 \%$ of patients receiving concomitant lactulose) to reduce the risk of overt $\mathrm{HE}$ decreased mean annual inpatient admission costs compared with the year prior to rifaximin (£12,522 per year before rifaximin vs. $\$ 5915$ per year after rifaximin; provider perspective) [55] (Table 3) [55, 57-62]. When considering 
Table 2 Effects of rifaximin on healthcare resource utilization $[55,56]$

\begin{tabular}{|c|c|c|c|c|c|}
\hline \multirow[t]{2}{*}{ Study; country } & \multirow{2}{*}{$\begin{array}{l}\text { Centre } \\
\text { (pts), } n\end{array}$} & \multirow{2}{*}{$\begin{array}{l}\text { Data } \\
\text { collection }\end{array}$} & \multicolumn{3}{|c|}{ Outcomes (prior to rifaximin vs. with rifaximin ${ }^{\mathrm{a}}$ ) } \\
\hline & & & Month 3 & Month 6 & Month 12 \\
\hline $\begin{array}{l}\text { Orr et al. } 2016 \\
\text { [55], UK }\end{array}$ & $7(326)$ & 2014 & $\begin{array}{l}\text { Mean all-cause } \\
\text { hospitalizations }{ }^{\text {b }: ~} 1.2 \text { vs. } 0.6 \\
(p<0.001) \\
\text { Mean hospital LOS }(d)^{\text {b }} \text { : } \\
15.8 \text { vs. } 7.4(p<0.001)\end{array}$ & $\begin{array}{l}\text { Mean all-cause } \\
\text { hospitalizations }^{\mathrm{b}}: 1.6 \text { vs. } 1.0 \\
(p<0.001) \\
\text { Mean hospital } \operatorname{LOS}(\mathrm{d})^{\mathrm{b}} \text { : } \\
20.7 \text { vs. } 9.7(p<0.001)\end{array}$ & $\begin{array}{l}\text { Mean all-cause } \\
\text { hospitalizations }{ }^{\text {b: }} 2.1 \text { vs. } 1.6 \\
(p=0.001) \\
\text { Mean hospital LOS }(\mathrm{d})^{\text {b }: ~} 24.4 \\
\quad \text { vs. } 11.5(p<0.001)\end{array}$ \\
\hline $\begin{array}{l}\text { Aspinall et al. } \\
2016 \text { [56], UK }\end{array}$ & $\begin{array}{l}11 \\
(145)\end{array}$ & $\begin{array}{l}\text { July } 2008- \\
\text { May } 2014\end{array}$ & Not reported & $\begin{array}{l}\text { Mean hospitalizations: } 2.2 \text { vs. } \\
1.0(p<0.001) \\
\text { Total inpatient bed days: } 28.6 \\
\text { vs. } 11.9(p<0.001) \\
\text { Critical care bed days/pt: } 7.9 \\
\quad \text { vs. } 2.0(p=0.046) \\
\text { ER visits/pt: } 1.9 \text { vs. } 1.0 \\
\quad(p<0.001)\end{array}$ & $\begin{array}{l}\text { Mean hospitalizations: } 2.7 \text { vs. } \\
1.7(p=0.002) \\
\text { Total inpatient bed days: } 31.7 \\
\text { vs. } 16.4(p<0.001) \\
\text { Critical care bed days/pt: } 11.3 \\
\quad \text { vs. } 2.4(p=0.017) \\
\text { ER visits/pt: } 2.4 \text { vs. } 1.8 \\
(p=0.099)\end{array}$ \\
\hline
\end{tabular}

$d$ day, ER emergency room, LOS length of stay, $p t$ patient

${ }^{a}$ Time points for outcomes assessed after rifaximin was initiated

$\mathrm{b}_{n}=158$

the annual cost of rifaximin at the time of the study (£3379), the mean annual cost savings per patient were $£ 3228$ [55].

In France, rifaximin plus lactulose had a favourable pharmacoeconomic profile compared with lactulose monotherapy, based on a societal willingness-to-pay costeffectiveness threshold of $€ 27,000$ (Table 3); the incremental cost-effectiveness ratio of rifaximin to lactulose was $€ 18,517$ per each quality-adjusted life-year gained over 5 years, suggesting that rifaximin in combination with lactulose was a cost-effective treatment for patients with a history of at least two HE episodes [57]. In the USA and other countries, clinically relevant benefits of rifaximin (e.g. reduction in hospitalizations, decreased mortality rate, reversal of $\mathrm{HE}$ symptoms, maintenance of remission of $\mathrm{HE}$ ) have been demonstrated in pharmacoeconomic studies (Table 3) [55, 57-62]. Finally, applying the 50\% reduction in HE-related hospitalizations attributable to rifaximin by Bass et al. [39] to the 22,931 HE-related hospitalizations at \$US63,107 annual inpatient charges per episode reported by Stepanova et al. [31] reveals a potential inpatient cost avoidance for the payer of $>$ \$US723 million annually in the USA (2009 values). However, this cost avoidance potential must be considered within the context of charges as a valuation vs. actual costs, any additional costs of therapy, potential cost savings for other direct medical costs and indirect costs, the potential increases in both the incidence and the cost of HE-related hospitalizations since 2009 , and the number of patients treated.

\section{Discussion}

In this systematic review, the global economic costs associated with HE-related healthcare utilization are summarized for the past 10 years. Patients with HE, regardless of geographic location, present a substantial economic burden on the healthcare infrastructure, and annual hospitalizations for patients with HE can be quite costly to the healthcare system. Mean duration of hospital stay related to HE ranged between 5.9 [32] and 9 days [21, 27] in the literature, with a mean of 2.4 yearly hospitalizations for patients with HE [32]. A study of patients previously hospitalized for liver disease showed a mean 1.5 HE-related readmissions annually [13]. Overall, data suggest that initiating rifaximin therapy early in the hospital setting could lead to decreased length of stay [55]. Furthermore, the cost savings estimated for rifaximin vs. lactulose, while based on published estimates of numbers affected, support the idea that reducing the risk of hospitalization in patients with HE would significantly reduce the economic burden to healthcare systems for this condition. Indeed, the incremental costs of rifaximin are outweighed by the potential savings in healthcare costs.

Irish et al. [32] demonstrated that patients with $\mathrm{HE}$ enrolled in a government-sponsored healthcare programme had an average of 11 outpatient visits annually. The literature suggests that rifaximin may provide better control of HE symptoms and, in turn, may reduce not only hospitalization-related costs and duration of hospital stay but also other healthcare-related costs, especially if rifaximin use translates into reduced need for ambulatory follow-up 
Table 3 Pharmacoeconomic profile of rifaximin

\begin{tabular}{|c|c|c|c|}
\hline Country & Patient characteristics & Endpoint(s) and model & Outcomes \\
\hline $\begin{array}{l}\text { Belgium } \\
\text { [61] }\end{array}$ & Recurrent overt HE & $\begin{array}{l}\text { ICER, derived from QALY } \\
\text { Markov state transition model }\end{array}$ & $\begin{array}{l}\text { Lactulose (SOC) } \\
\text { Average cost (2010): } € 44,190 \\
1.9 \text { QALY/pt } \\
\text { Average cost effectiveness: } € 23,258 / \mathrm{QALY} \\
\text { Rifaximin + lactulose } \\
\text { Average cost: } € 31,262 \\
2.5 \text { QALY/pt } \\
\text { Average cost effectiveness: } € 12,505 / \mathrm{QALY} \\
\text { ICER: } € 21,547 / \mathrm{Q} A L Y \text { for rifaximin + lactulose vs. lactulose }\end{array}$ \\
\hline France [57] & $\begin{array}{l}\text { History of overt HE ( } \geq 2 \\
\text { episodes); currently in } \\
\text { remission }\end{array}$ & $\begin{array}{l}\text { ICER, derived from QALY } \\
\text { Markov state transition model }\end{array}$ & $\begin{array}{l}\text { Lactulose (SOC) } \\
2 \text { years } \\
\text { Cost: €5503 } \\
0.967 \mathrm{QALY} / \mathrm{pt} \\
5 \text { years } \\
\text { Cost: } € 8555 \\
1.778 \text { QALY/pt } \\
\text { Rifaximin }+ \text { lactulose } \\
2 \text { years } \\
\text { Cost: } € 7639 \\
1.078 \mathrm{LY} / \mathrm{pt} \\
5 \text { years } \\
\text { Cost: } € 14,411 \\
2.094 \text { QALY } \\
\text { ICER } \\
2 \text { years: } € 19,187 / \mathrm{QALY} \text { for rifaximin + lactulose vs. lactulose } \\
5 \text { years: } € 18,517 / \mathrm{QALY} \text { for rifaximin + lactulose vs. lactulose }\end{array}$ \\
\hline $\begin{array}{l}\text { Netherlands } \\
\text { [59] }\end{array}$ & Recurrent overt HE & $\begin{array}{l}\text { ICER, derived from QALY } \\
\text { Markov state transition model }\end{array}$ & $\begin{array}{l}\text { Lactulose (SOC) } \\
\text { Average cost (2010): } € 82,968 \\
1.89 \text { QALY/pt } \\
\text { Rifaximin + lactulose } \\
\text { Average cost: } € 88,386 \\
2.45 \text { QALY/pt } \\
\text { ICER (5 years): €9576/QALY for rifaximin + lactulose vs. } \\
\text { lactulose }\end{array}$ \\
\hline Sweden [60] & Recurrent overt HE & $\begin{array}{l}\text { ICER, derived from QALY } \\
\text { Markov state transition model }\end{array}$ & $\begin{array}{l}\text { Lactulose (SOC) } \\
\text { Average cost (2012): } € 42,522 \\
1.83 \text { QALY/pt } \\
\text { Rifaximin + lactulose } \\
\text { Average cost: } € 32,667 \\
2.38 \text { QALY/pt } \\
\text { ICER ( } 5 \text { years): } € 17,918 / \text { QALY for rifaximin + lactulose vs. } \\
\text { lactulose }\end{array}$ \\
\hline UK [55] & Overt $\mathrm{HE}^{\mathrm{a}}$ & Cost analysis of rifaximin & $\begin{array}{l}\text { Mean annual emergency inpatient admission costs, } 1 \text { year before } \\
\text { vs. } 1 \text { year after rifaximin: } £ 12,522 \text { vs. £5915, respectively } \\
\text { ( } 2013 / 2014 \text { costs) }\end{array}$ \\
\hline
\end{tabular}


Table 3 continued

\begin{tabular}{|c|c|c|c|}
\hline Country & Patient characteristics & Endpoint(s) and model & Outcomes \\
\hline UK [58] & Recurrent overt HE & $\begin{array}{l}\text { ICER, derived from QALY } \\
\text { Markov state transition model }\end{array}$ & $\begin{array}{l}\text { Lactulose (SOC) } \\
\text { Average cost (2012): } 23,545 \\
1.83 \mathrm{QALY} / \mathrm{pt} \\
\text { Rifaximin } \\
\text { Average cost: } 22,971 \\
2.36 \mathrm{QALY} / \mathrm{pt} \\
\text { ICER } \\
5 \text { years: £1083/QALY for rifaximin vs. lactulose } \\
10 \text { years: £4470/QALY for rifaximin vs. lactulose } \\
\text { Lifetime: } £ 7215 / \mathrm{Q} A L Y \text { for rifaximin vs. lactulose }\end{array}$ \\
\hline USA [62] & Recurrent overt HE & $\begin{array}{l}\text { Costs (drug costs, } \\
\text { hospitalizations, liver } \\
\text { transplant) } \\
\text { Outcomes (hospitalizations, } \\
\text { LY, QALY) }\end{array}$ & $\begin{array}{l}\text { Rifaximin + lactulose vs. lactulose } \\
\text { Life expectancy improved with rifaximin + lactulose vs. } \\
\text { lactulose (lifetime, } 5.7 \text { vs. } 2.8 \text { years) } \\
\text { Opportunity for liver transplant improved } 2 \text {-fold with rifaximin } \\
\text { + lactulose vs. lactulose } \\
\text { Hospitalizations were decreased with rifaximin + lactulose vs. } \\
\text { lactulose over } 6 \text { mo }(0.27 / p t \text { vs. } 0.51 / p t) \\
\text { Lifetime cost of rifaximin: \$US } 59,777 \\
\text { \$US 20,287/LY for rifaximin + lactulose vs. lactulose } \\
\text { \$US 26,672/QALY for rifaximin + lactulose vs. lactulose }\end{array}$ \\
\hline
\end{tabular}

$H E$ hepatic encephalopathy, ICER incremental cost-effectiveness ratio, $L Y$ life-years, $Q A L Y$ quality-adjusted life years, $S O C$ standard of care ${ }^{a}$ In this study, costs were compared before and after initiation of rifaximin

$[39,45]$. However, more research is needed to confirm and quantify the extent to which rifaximin use may reduce healthcare-related costs.

Rifaximin with or without lactulose is associated with improvement in both the number and the duration of hospitalizations in patients with HE $[55,56]$. Further, studies conducted in different countries demonstrated that rifaximin combined with lactulose had a more favourable costeffectiveness profile than lactulose alone [55, 57-62]. It should be noted that the data presented in some of these studies are in the form of meeting abstracts [32, 56, 58-62], thus limiting the details presented regarding study design and outcomes (Table 4) [21, 25-32, 55-62].

A limitation of the current systematic review is that available data originate from multiple countries and often involve different timeframes. Variances in healthcare systems worldwide may limit the generalizability of the economic findings to a single country. Guidelines from the AASLD and EASL recommend lactulose as first-line therapy and rifaximin as add-on therapy for reducing the risk of recurrence of overt HE [1]. Another limitation of the current review is the paucity of economic data published for management of overt HE. This review included any publications meeting inclusion criteria since 2007; thus, two systematic reviews of costs in the USA and the rest of the world were included [25, 26]. Further, as shown in Table 4 , most of the cost data presented in the current systematic review did not undergo adjustment (e.g. to medical consumer price index), restricting head-to-head comparisons. Finally, while the pharmacoeconomic benefits of rifaximin appear to be favourable, a more thorough analysis is warranted to provide a current estimate of savings to the US healthcare system. Any such study utilizing more current estimates of the number of patients with cirrhosis and HE should employ sensitivity analyses representing higher prevalence estimates, given that the prevalence of cirrhosis and overt HE is likely underestimated [63] for several reasons, including nonspecific ICD10 diagnosis coding.

\section{Conclusions}

Rifaximin, either alone or in combination with lactulose, improved outcomes in patients with HE compared with lactulose alone. Rifaximin (with or without lactulose) decreased healthcare resource utilization in patients with overt $\mathrm{HE}$ and was associated with a favourable pharmacoeconomic profile compared with lactulose alone. Economic data are favourable for use of rifaximin (with or 
Systematic Review of the Economic Burden of Overt Hepatic Encephalopathy and Pharmacoeconomic...

819

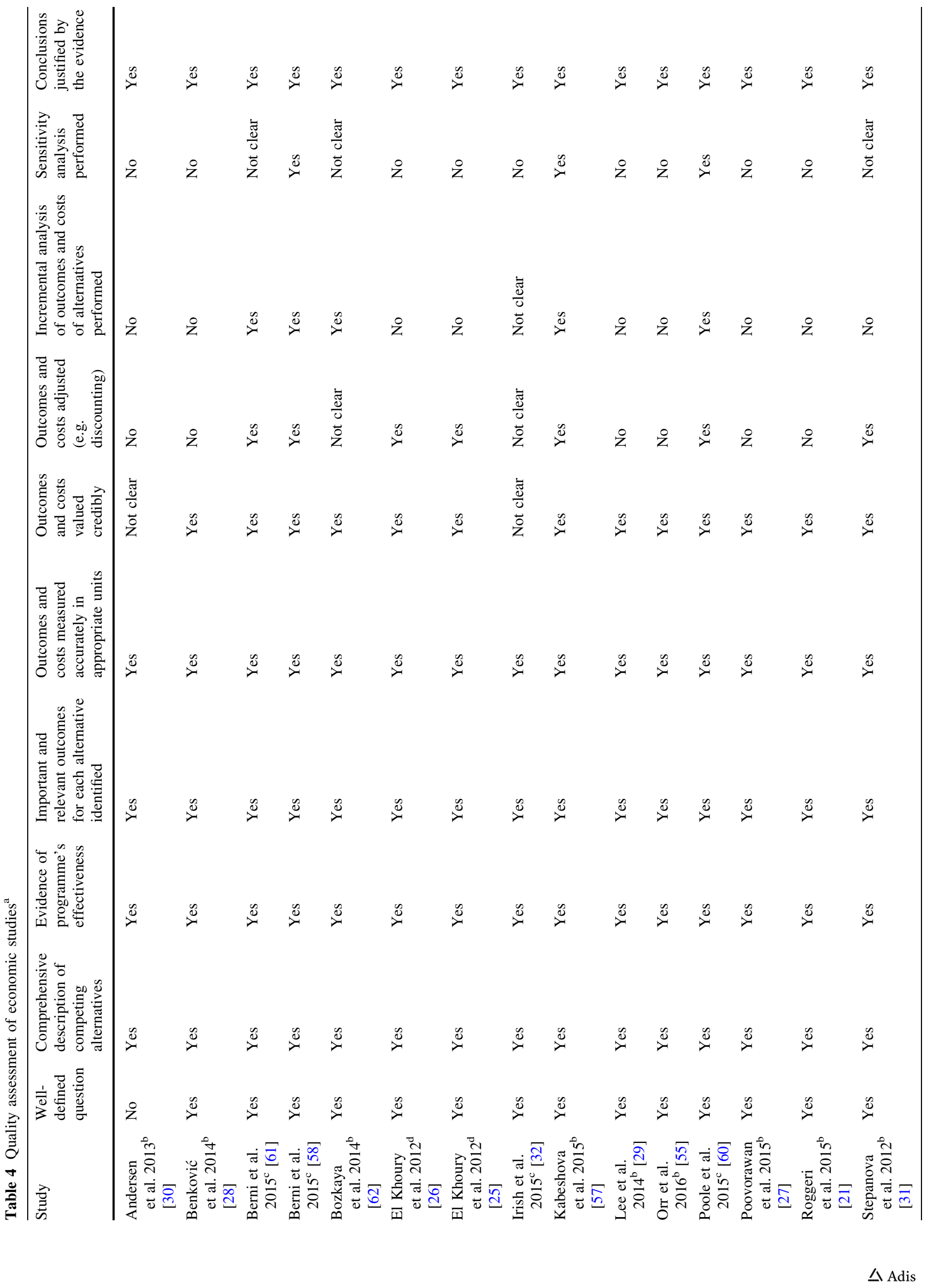




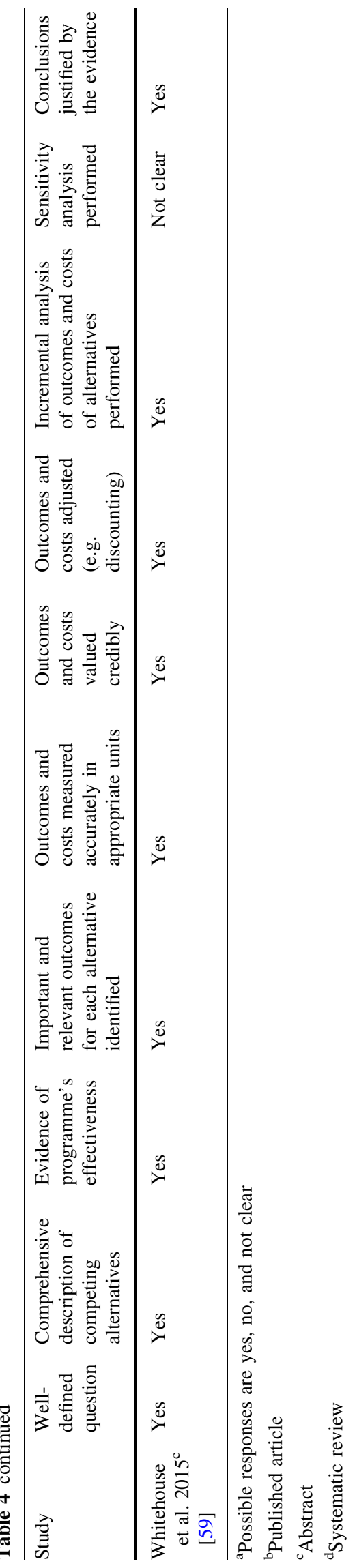

without lactulose) for reducing the risk of overt $\mathrm{HE}$ recurrence in patients with a history of overt HE. Therefore, reducing the risk of recurrence of overt HE (e.g. with rifaximin) to reduce hospital readmission should be a consideration at discharge for adults with cirrhosis who were hospitalized due to overt HE.

Data availability statement Data sharing information is not applicable to this article as no datasets were generated or analysed during the current study.

Author contributions GN and WZ contributed to the concept and objective of the article, established the parameters around the systematic review, and interpreted and critiqued the data. GN and WZ were involved in drafting and commenting on the article and approved the final version for submission. Guarantor: GN acts as the guarantor for this work.

\section{Compliance with Ethical Standards}

Funding Technical editorial assistance was provided, under the direction of the authors, by Mary Beth Moncrief, $\mathrm{PhD}$, and Sophie Bolick, PhD, Synchrony Medical Communications, LLC, West Chester, PA, USA. Funding for this support was provided by Salix Pharmaceuticals, Bridgewater, NJ, USA.

Conflict of interest GN and WZ have no potential conflicts of interest that are relevant to the content of this article and neither they nor their respective institutions received funding for the manuscript. Salix Pharmaceuticals did not actively participate in content development but reviewed the manuscript for scientific accuracy. As disclosed in the funding statement, Salix Pharmaceuticals provided support for technical editorial assistance.

Open Access This article is distributed under the terms of the Creative Commons Attribution-NonCommercial 4.0 International License (http://creativecommons.org/licenses/by-nc/4.0/), which permits any noncommercial use, duplication, adaptation, distribution and reproduction in any medium or format, as long as you give appropriate credit to the original author(s) and the source, a link is provided to the Creative Commons license and any changes made are indicated.

\section{References}

1. Vilstrup H, Amodio P, Bajaj J, Cordoba J, Ferenci P, Mullen KD, et al. Hepatic encephalopathy in chronic liver disease: 2014 practice guideline by the American Association for the Study of Liver Diseases and the European Association for the Study of the Liver. Hepatology. 2014;60(2):715-35.

2. Romero-Gómez M, Boza F, García-Valdecasas MS, García E, Aguilar-Reina J. Subclinical hepatic encephalopathy predicts the development of overt hepatic encephalopathy. Am J Gastroenterol. 2001;96(9):2718-23.

3. Patidar KR, Bajaj JS. Covert and overt hepatic encephalopathy: diagnosis and management. Clin Gastroenterol Hepatol. 2015;13(12):2048-61.

4. Bajaj JS, Wade JB, Sanyal AJ. Spectrum of neurocognitive impairment in cirrhosis: implications for the assessment of hepatic encephalopathy. Hepatology. 2009;50(6):2014-21. 
5. Bajaj JS, Riggio O, Allampati S, Prakash R, Gioia S, Onori E, et al. Cognitive dysfunction is associated with poor socioeconomic status in patients with cirrhosis: an international multicenter study. Clin Gastroenterol Hepatol. 2013;11(11):1511-6.

6. Bajaj JS, Wade JB, Gibson DP, Heuman DM, Thacker LR, Sterling RK, et al. The multi-dimensional burden of cirrhosis and hepatic encephalopathy on patients and caregivers. Am J Gastroenterol. 2011;106(9):1646-53.

7. Bruyneel M, Serste T, Libert W, van den Broecke S, Ameye L, Dachy B, et al. Improvement of sleep architecture parameters in cirrhotic patients with recurrent hepatic encephalopathy with the use of rifaximin. Eur J Gastroenterol Hepatol. 2017;29(3):302-8.

8. Nardelli S, Allampati S, Riggio O, Mullen KD, Prakash R, Gioia $\mathrm{S}$, et al. Hepatic encephalopathy is associated with persistent learning impairments despite adequate medical treatment: a multicenter, international study. Dig Dis Sci. 2017;62(3):794-800.

9. Umapathy S, Dhiman RK, Grover S, Duseja A, Chawla YK. Persistence of cognitive impairment after resolution of overt hepatic encephalopathy. Am J Gastroenterol. 2014;109(7):1011-9.

10. Barboza KC, Salinas LM, Sahebjam F, Jesudian AB, Wesiberg IL, Sigal SH. Impact of depressive symptoms and hepatic encephalopathy on health-related quality of life in cirrhotic hepatitis C patients. Metab Brain Dis. 2016;31(4):869-80.

11. Arguedas MR, DeLawrence TG, McGuire BM. Influence of hepatic encephalopathy on health-related quality of life in patients with cirrhosis. Dig Dis Sci. 2003;48(8):1622-6.

12. Bannister CA, Orr JG, Reynolds AV, Hudson M, Conway P, Radwan A, et al. Natural history of patients taking rifaximin- $\alpha$ for recurrent hepatic encephalopathy and risk of future overt episodes and mortality: a post-hoc analysis of clinical trials data. Clin Ther. 2016;38(5):1081-9.

13. Di Pascoli M, Ceranto E, Nardi PD, Donato D, Gatta A, Angeli P, et al. Hospitalizations due to cirrhosis: clinical aspects in a large cohort of Italian patients and cost analysis report. Dig Dis. 2017;35:433-8.

14. Jinjuvadia R, Liangpunsakul S, Consortium TREAHT. Trends in alcoholic hepatitis-related hospitalizations, financial burden, and mortality in the United States. J Clin Gastroenterol. 2015;49(6):506-11.

15. Patidar KR, Thacker LR, Wade JB, White MB, Gavis EA, Fagan $A$, et al. Symptom domain groups of the patient-reported outcomes measurement information system tools independently predict hospitalizations and re-hospitalizations in cirrhosis. Dig Dis Sci. 2017;62(5):1173-9.

16. Atla PR, Sheikh MY, Gill F, Kundu R, Choudhury J. Predictors of hospital re-admissions among Hispanics with hepatitis C-related cirrhosis. Ann Gastroenterol. 2016;29(4):515-20.

17. Chirapongsathorn S, Krittanwong C, Enders F, Pendergast R, Mara K, Borah B, et al. Incidence and cost analysis of hospital admission and 30-day readmission among patients with cirrhosis. Hepatol Commun. 2018;2(2):188-98.

18. Tapper EB, Halbert B, Mellinger J. Rates of and reasons for hospital readmissions in patients with cirrhosis: a multistate population-based cohort study. Clin Gastroenterol Hepatol. 2016;14(8):1181-8.

19. Bajaj JS, Reddy KR, Tandon P, Wong F, Kamath PS, GarciaTsao G, et al. The 3-month readmission rate remains unacceptably high in a large North American cohort of patients with cirrhosis. Hepatology. 2016;64(1):200-8.

20. Martel-Laferrière V, Homberger C, Bichoupan K, Dieterich DT. MELD score and antibiotics use are predictors of length of stay in patients hospitalized with hepatic encephalopathy. BMC Gastroenterol. 2014;14:185.
21. Roggeri DP, Roggeri A, Rossi E, Cinconze E, Gasbarrini A, Monici Preti $\mathrm{P}$, et al. Overt hepatic encephalopathy in Italy: clinical outcomes and healthcare costs. Hepat Med. 2015;7:37-42.

22. ISPOR Scientific Presentations Database. https://www.ispor.org/ research_study_digest/research_index.asp. Accessed 21 June 2017.

23. US Department of Health and Human Services. Agency for Healthcare Research and Quality. Healthcare Cost and Utilization Project (HCUPnet) database. https://hcupnet.ahrq.gov/. Accessed 10 July 2017.

24. Drummond MF, Jefferson TO, The BMJ Economic Evaluation Working Party. Guidelines for authors and peer reviewers of economic submissions to the BMJ. BMJ. 1996;313(7052):275-83.

25. El Khoury AC, Klimack WK, Wallace C, Razavi H. Economic burden of hepatitis C-associated diseases in the United States. J Viral Hepat. 2012;19(3):153-60.

26. El Khoury AC, Wallace C, Klimack WK, Razavi H. Economic burden of hepatitis C-associated diseases: Europe, Asia Pacific, and the Americas. J Med Econ. 2012;15(5):887-96.

27. Poovorawan K, Treeprasertsuk S, Thepsuthammarat K, Wilairatana P, Kitsahawong B, Phaosawasdi K. The burden of cirrhosis and impact of universal coverage public health care system in Thailand: nationwide study. Ann Hepatol. 2015;14(6):862-8.

28. Benković V, Kolčić I, Ivičević Uhernik A, Vranešić Bender D, Oreb I, Stevanović R, et al. The economic burden of diseaserelated undernutrition in selected chronic diseases. Clin Nutr. 2014;33(4):689-93.

29. Lee PC, Yang YY, Lin MW, Hou MC, Huang CS, Lee KC, et al. Benzodiazepine-associated hepatic encephalopathy significantly increased healthcare utilization and medical costs of Chinese cirrhotic patients: 7-year experience. Dig Dis Sci. 2014;59(7):1603-16.

30. Andersen MM, Aunt S, Jensen NM, Homann C, Manniche J, Svendsen S, et al. Rehabilitation for cirrhotic patients discharged after hepatic encephalopathy improves survival. Dan Med J. 2013;60(8):A4683.

31. Stepanova M, Mishra A, Venkatesan C, Younossi ZM. In-hospital mortality and economic burden associated with hepatic encephalopathy in the United States from 2005 to 2009. Clin Gastroenterol Hepatol. 2012;10(9):1034-41.

32. Irish W, Saynisch P, Mallow PJ, Fallon L, Gunnarsson C. Using the Medicare claims database to understand the economic burden of liver disease: a case study in hepatic encephalopathy. In: ISPOR Scientific Presentations Database; 2015. https://www. ispor.org/RESEARCH_STUDY_DIGEST/research_index.asp. Accessed 11 July 2017.

33. Gluud LL, Vilstrup H, Morgan MY. Non-absorbable disaccharides versus placebo/no intervention and lactulose versus lactitol for the prevention and treatment of hepatic encephalopathy in people with cirrhosis. Cochrane Database Syst Rev. 2016;5:CD003044.

34. Agarwalla A, Weber A, Davey S, Hamilton K, Goldberg D, Rhim $\mathrm{AD}$, et al. Lactulose is associated with decreased risk of Clostridium difficile infection in decompensated cirrhosis. Clin Gastroenterol Hepatol. 2017;15(6):953-4.

35. Bajaj JS, Ananthakrishnan AN, Hafeezullah M, Zadvornova Y, Dye A, McGinley EL, et al. Clostridium difficile is associated with poor outcomes in patients with cirrhosis: a national and tertiary center perspective. Am J Gastroenterol. 2010;105(1):106-13.

36. Sharma BC, Sharma P, Lunia MK, Srivastava S, Goyal R, Sarin SK. A randomized, double-blind, controlled trial comparing rifaximin plus lactulose with lactulose alone in treatment of overt 
hepatic encephalopathy. Am J Gastroenterol. 2013;108(9):1458-63.

37. Vlachogiannakos J, Viazis N, Vasianopoulou P, Vafiadis I, Karamanolis DG, Ladas SD. Long-term administration of rifaximin improves the prognosis of patients with decompensated alcoholic cirrhosis. J Gastroenterol Hepatol. 2013;28(3):450-5.

38. Courson A, Jones GM, Twilla JD. Treatment of acute hepatic encephalopathy: comparing the effects of adding rifaximin to lactulose on patient outcomes. J Pharm Pract. 2016;29(3):212-7.

39. Bass NM, Mullen KD, Sanyal A, Poordad F, Neff G, Leevy CB, et al. Rifaximin treatment in hepatic encephalopathy. N Engl J Med. 2010;362(12):1071-81.

40. Kimer N, Krag A, Møller S, Bendtsen F, Gluud LL. Systematic review with meta-analysis: the effects of rifaximin in hepatic encephalopathy. Aliment Pharmacol Ther. 2014;40(2):123-32.

41. Neff GW, Jones M, Broda T, Jonas M, Ravi R, Novick D, et al. Durability of rifaximin response in hepatic encephalopathy. J Clin Gastroenterol. 2012;46(2):168-71.

42. Tapper EB, Finkelstein D, Mittleman MA, Piatkowski G, Chang M, Lai M. A quality improvement initiative reduces 30-day rate of readmission for patients with cirrhosis. Clin Gastroenterol Hepatol. 2016;14(5):753-9.

43. Bajaj JS, Barrett AC, Bortey E, Paterson C, Forbes WP. Prolonged remission from hepatic encephalopathy with rifaximin: results of a placebo crossover analysis. Aliment Pharmacol Ther. 2015;41(1):39-45.

44. Lyon KC, Likar E, Martello JL, Regier M. Retrospective crosssectional pilot study of rifaximin dosing for the prevention of recurrent hepatic encephalopathy. J Gastroenterol Hepatol. 2017;32(9):1548-52.

45. Mullen KD, Sanyal AJ, Bass NM, Poordad FF, Sheikh MY, Frederick RT, et al. Rifaximin is safe and well tolerated for longterm maintenance of remission from overt hepatic encephalopathy. Clin Gastroenterol Hepatol. 2014;12(8):1390-7.

46. Mantry PS, Mehta A, Graydon R. Efficacy and tolerability of rifaximin in combination with lactulose in end-stage liver disease patients with MELD greater than 20: a single center experience. Transpl Proc. 2014;46(10):3481-6.

47. Hammond DA, Dayama N, Martin BC, editors. Impact of rifaximin and lactulose versus lactulose alone on hospitalization for acute recurrent hepatic encephalopathy. Boston: International Society for Pharmacoeconomics and Outcomes Research; 2017.

48. Congly SE, Leise MD. Rifaximin for episodic, overt hepatic encephalopathy: the data are catching up to clinical practice, but questions remain. Am J Gastroenterol. 2014;109(4):598.

49. Bajaj JS, Riggio O. Drug therapy: rifaximin. Hepatology. 2010;52(4):1484-8.

50. Leevy CB, Phillips JA. Hospitalizations during the use of rifaximin versus lactulose for the treatment of hepatic encephalopathy. Dig Dis Sci. 2007;52(3):737-41.
51. Bajaj JS, Sanyal AJ, Bell D, Gilles H, Heuman DM. Predictors of the recurrence of hepatic encephalopathy in lactulose-treated patients. Aliment Pharmacol Ther. 2010;31(9):1012-7.

52. Rassameehiran S, Mankongpaisarnrung C, Sutamtewagul G, Klomjit S, Rakvit A. Predictor of 90-day readmission rate for hepatic encephalopathy. South Med J. 2016;109(6):365-9.

53. Volk ML, Tocco RS, Bazick J, Rakoski MO, Lok AS. Hospital readmissions among patients with decompensated cirrhosis. Am J Gastroenterol. 2012;107(2):247-52.

54. Wu D, Wu SM, Lu J, Zhou YQ, Xu L, Guo CY. Rifaximin versus nonabsorbable disaccharides for the treatment of hepatic encephalopathy: a meta-analysis. Gastroenterol Res Pract. 2013;2013:236963.

55. Orr JG, Currie CJ, Berni E, Goel A, Moriarty KJ, Sinha A, et al. The impact on hospital resource utilisation of treatment of hepatic encephalopathy with rifaximin- $\alpha$. Liver Int. 2016;36(9):1295-303.

56. Aspinall R, Radwan A, Shaya G, Sodatonou H, Cipelli R. The impact of rifaximin- $\alpha$ on NHS hospital resource use in UK patients with hepatic encephalopathy: a retrospective observational study (Impress). J Hepatol. 2016;64:S283.

57. Kabeshova A, Ben Hariz S, Tsakeu E, Benamouzig R, Launois R. Cost-effectiveness analysis of rifaximin- $\alpha$ administration for the reduction of episodes of overt hepatic encephalopathy in recurrence compared with standard treatment in France. Ther Adv Gastroenterol. 2016;9(4):473-82.

58. Berni E, Poole CD, Conway P, Radwan A, Currie CJ. Cost effectiveness of rifaximin- $\alpha 550 \mathrm{mg}$ in the reduction of recurrence of overt hepatic encephalopathy in United Kingdom. Value Health. 2015;18(7):A626.

59. Whitehouse JT, Berni E, Conway P, Radwan A, Henrar R, Currie CJ. Evaluation of the cost effectiveness and societal impact of rifaximin- $\alpha 550 \mathrm{mg}$ in the reduction of recurrence of overt hepatic encephalopathy in The Netherlands. Value Health. 2015;18(7):A629.

60. Poole CD, Berni E, Conway P, Radwan A, Currie CJ. Evaluation of the cost effectiveness of rifaximin- $\alpha 550 \mathrm{mg}$ in the reduction of recurrence of overt hepatic encephalopathy in Sweden. Value Health. 2015;18(7):A626.

61. Berni E, Connolly M, Conway P, Radwan A, Currie CJ. Evaluation of the cost effectiveness of rifaximin- $\alpha$ in the reduction of recurrence of overt hepatic encephalopathy in Belgium. Value Health. 2015;18(7):A628.

62. Bozkaya D, Barrett AC, Migliaccio-Walle K. Cost-effectiveness of rifaximin treatment in patients with hepatic encephalopathy. Hepatology. 2014;60(4 Suppl):389A-90A.

63. Sandler RS, Everhart JE, Donowitz M, Adams E, Cronin K, Goodman $\mathrm{C}$, et al. The burden of selected digestive diseases in the United States. Gastroenterology. 2002;122(5):1500-11. 